\title{
Surface characteristics of titanium with rotary EDM
}

\author{
J S SONI and G CHAKRAVERTI* \\ Defence Research and Development Laboratory, Hyderabad 500258 , India \\ * Mechanical Engineering Department, JNTU College of Engineering, Hyderabad 500872 , \\ India \\ MS received 27 November 1992

\begin{abstract}
Experimental investigations have been carried out on electro-discharge machining of titanium in respect of surface finish, out-of-roundness and overcut using rotating copper-tungsten tool electrode. An attempt has also been made to compare the results with stationary electrode.

It is concluded that rotation of electrode improves out-of-roundness, surface roughness, overcut and out-of-roundness increase with increase of current with both rotating and stationary electrodes.
\end{abstract}

Keywords. Electro-discharge machining, rotary EDM: rotating electrode; out-ofroundness.

\section{Introduction}

Electro-discharge machining (EDM) is one of the non-traditional machining methods widely used on electrically conducting materials such as high strength temperature resistance (HSTR) alloys, tough, fragile, with varied physico-chemical and mechanical properties. EDM has been successfully used to generate complicated profiles and holes of micro-dimensions and has found an important place in machining with growing demand for components of higher accuracy, longer life and better quality. Titanium is a widely used material in aerospace applications due to its low weight to high strength ratio, where dimensional accuracy and better surface quality are the governing factors (Soni and Chakraverti 1990a).

Orbital motion of electrode permits one to correct, to some extent, form and dimensional accuracy in machining process, performs roughing and finishing operations with the same tool electrode and helps in stabilizing the erosion process. Where it is not feasible to have forced suction flushing, alternate methods to clear the debris effectively from the gap between the electrodes in EDM have been attempted (Kravets 1977; De Bruyn and Delft 1978; Erden 1982; Masuzawa and Heuvelman 1983; Murthi and Philip 1987).

Researchers so far have concentrated on other means of clearing the debris from the gap between the electrode and workpiece without using the rotating electrode. Some researchers (Radhakrishnan and Achyutha 1980; Ayers and Moore 1984) have discussed the craters formed by single discharge and formation of metal carbide powder with stationary electrode using titanium as work material while others (Kagaya et al 1986; Sato et al 1986) have presented the micro-hole drilling and boring of stainless steel and other materials by using rotating electrodes. Keneko and Tsuchiya (1988) reported 3 DNC contouring by EDM with compensation. Faruqui and Mishra (1978) studied the effect of super position of hydrostatic pressure in EDM.

Inherent phenomena of EDM such as short circuit, open circuit and arcing pulses 
reduces sparking efficiency and results in poor performance. Sparking efficiency is still further reduced in drilling or cavity sinking and frequent short circuits occur due to excessive debris concentration in the spark gap. This needs effective clearance of debris from the gap between the electrode and workpiece (Faruqui and Mishra 1978). Some authors (Kagaya et al 1986; Sato et al 1986; Soni and Chakraverti 1990b) have reported improvement in flushing of debris and machining characteristics using rotating electrodes.

Due to development of new materials and requirement of high quality products, it is necessary to establish the machining parameters to face these challenges. The literature survey shows that detailed investigations have not been carried out on titanium machining using the rotating electrode. Hence, the need to investigate the machining characteristics and generate sufficient data by comparing the machining of titanium using stationary and rotating copper-tungsten electrodes (figures 1-3).

Response surface technique was adopted for comparing the performance of the rotary EDM, since such technological surface serve as objective criteria for comparing EDM systems. Moreover, such a surface and its response function serve as a mathematical model of the process.

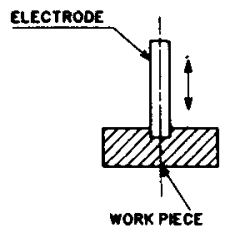

(o)

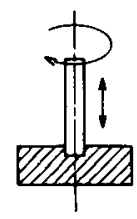

(b)

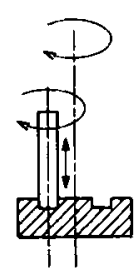

(c)

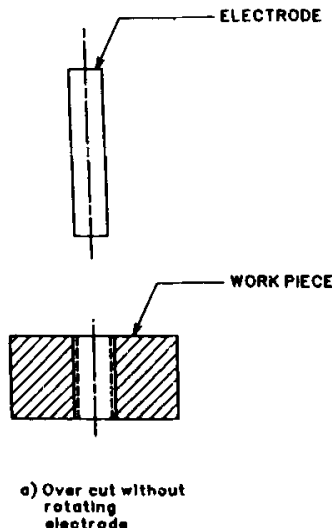

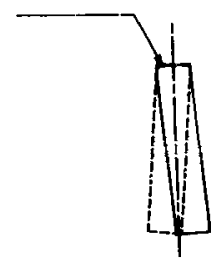

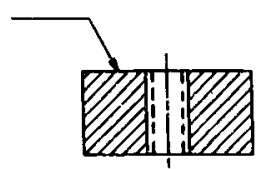

b) Over out with rotating.

Figure 1. Electro-discharge machining with (a) stationary electrode, (b) rotating electrode and (c) rotating electrode with orbital motion.

Figure 2. Over-cut with and without rotating electrodes.

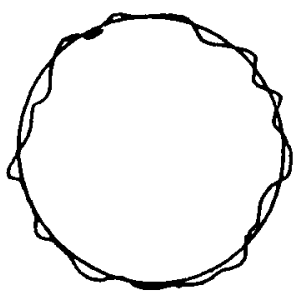

a) Out of roundness without rotating electrode

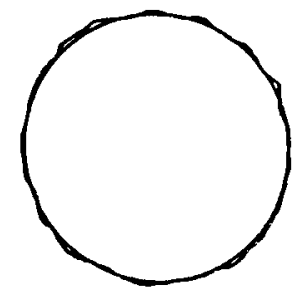

b) Out of roundness with rotating electrode

Figure 3. Out-of-roundness with and without rotating electrodes. 


\section{Experimental details}

Fine Sodik Mark 5 CNC EDM with servo control and rotating heads with variable speeds for electrodes was used to conduct the experiments. Table 1 gives the properties of the material used and the process parameters.

\subsection{Measurements}

Surface roughness was measured and surface profilographs were taken on Surtronic-3 with $\mathrm{Ra}$ value at a cut-off length of $0.8 \mathrm{~mm}$. An optical microscope was used to measure the diameter of the eroded hole. The diameter of the electrode was measured using a micrometer with a least count of $0.001 \mathrm{~mm}$.

The photomicrographs of holes were taken at magnification $(\times 16)$ on metallurgical microscope. Out-of-roundness was measured with Taly Rond at magnification $(\times 500)$.

\subsection{Design of experiments}

The experimental work was planned on the basis of statistical design of experiments. Hence, a complete $3^{2}$ factorial experimental model was formulated with full

Table 1.

$\begin{array}{ll}\text { Work and tool material properties: } & \\ \text { Work material } & : \text { Titanium, Ti } 6 \mathrm{~A} 14 \mathrm{~V} \\ \text { Work shape and size } & : \text { Square shape and size }(25 \times 25 \times 10 \mathrm{~mm}) \\ \text { Density } & : 4500 \mathrm{~kg} / \mathrm{m}^{3} \\ \text { Hardness } & : 28 \mathrm{HRc} \\ \text { Tool material } & : \text { Copper-tungsten }(\mathrm{W} 80, \mathrm{Cu} 20) \\ \text { Tool shape and size } & : \text { Cylindrical shape of diameter }(3 \mathrm{~mm}) \\ \text { Density } & : 14700 \mathrm{~kg} / \mathrm{m}^{3} \\ \text { Hardness } & : 170 \mathrm{BHN} \\ & \\ \text { Process parameters } & \\ & \\ \text { Dielectric } & : \text { Kerosene (commercial grade) } \\ \text { Voltage } & : 90 \mathrm{~V} \\ \text { Current } & : 3,9,15 \mathrm{amp} \\ \text { On puise duration } & : 20,200 \mu \text { sec } \\ \text { Electrode rotating speed } & : 0,500,750,1000 \text { rpm } \\ \text { Type of machining } & : \text { Through and blind hole machining. For } \\ & \text { through hole machining, the work pieces } \\ & \text { were predrilled with } 2 \text { mm diameter } \\ & \text { holes. }\end{array}$


Table 2. Design scheme of the experiment.

\begin{tabular}{|c|c|c|c|c|c|}
\hline \multirow[b]{2}{*}{ Response } & \multirow[b]{2}{*}{ Factors } & \multicolumn{3}{|c|}{ Coded levels } & \multirow[b]{2}{*}{ Remarks } \\
\hline & & -1 & 0 & 1 & \\
\hline Surface roughness $(R a, \mu \mathrm{m})$ & $\mathrm{X}_{1}$ Current (amp) & 3 & 9 & 15 & $\begin{array}{l}\text { Pulse duration } \\
\text { constant }(20 \mu \mathrm{s})\end{array}$ \\
\hline $\begin{array}{l}\text { Surface roughness profiles } \\
\text { Out-of-roundness }(\mu \mathrm{m}) \\
\text { Round hole roughness profiles } \\
\text { Over-cut }(\mathrm{mm})\end{array}$ & $\mathrm{X}_{2}$ Electrode rotation (RPM) & 500 & 750 & 1000 & \\
\hline
\end{tabular}

randomization with the help of a random number table (Cochran et al 1977). To simplify the data, the levels were set at equal intervals and the resulting orthogonal contrasts facilitated easy computation of the regression coefficients (Das and Giri 1986). The scheme of experiment plan, along with the factors and their coded levels are given in table 2.

The total number of regression coefficients, $N$, possible is given by the expression (Murthi and Philip 1987)

$$
N=\frac{1}{2}[n(n+3)]+1
$$

where $n$ is the number of factors.

For a two-factor experiment, six regression coefficients are possible. Accordingly, it is assumed that a second-order polynomial would be adequate to represent the response surface. The adequacy of fit can be further checked by the coefficient of correlation.

The mathematical model of the process is given here. A general model of the process can be expressed as:

$$
\eta=\phi\left(x_{1}, x_{2}, \ldots, x_{k}\right)
$$

where $\eta$ is the response variable, $\phi$, the response function and $x_{1}, x_{2}, \ldots, x_{k}$ are selected factors. A second-order polynomial representation of the response surface is given as

$$
\eta=\beta_{0}+\beta_{1} x_{1}+\beta_{2} x_{2}+\beta_{11} x_{1}^{2}+\beta_{22} x_{2}^{2}+\beta_{12} x_{1} x_{2},
$$

where the coefficient $\beta_{0}$ represents the response at the centre of the experiment and the coefficients $\beta_{1}, \beta_{2}, \beta_{11}, \beta_{22}$ and $\beta_{12}$ represent the linear, quadratic and linear $x$ linear interaction effect of the factors $x_{1}$ and $x_{2}$ respectively.

The regression coefficients and the coefficient of correlation $(r)$ were computed according to the standard statistical procedure. A complete analysis of variance (ANOVA) was performed to test the significance of the coefficients obtained at $5 \%$ level of significance. The procedure is illustrated in table 4 . The adequacy of the proposed model was tested by comparing the variance. The computed values of the regression coefficients are also given in table 3. 
Table 3. Regression coefficients for surface roughness, over-cut and out-of-roundness for titanium.

\begin{tabular}{|c|c|c|c|c|c|c|c|}
\hline \multirow{2}{*}{$\begin{array}{l}\text { Measured } \\
\text { response }\end{array}$} & \multicolumn{6}{|c|}{ Regression coefficients } & \multirow[b]{2}{*}{$F$ ratio } \\
\hline & $\beta_{0}$ & $\beta_{1}$ & $\beta_{2}$ & $\beta_{11}$ & $\beta_{22}$ & $\beta_{12}$ & \\
\hline $\begin{array}{l}\text { Surface } \\
\text { roughness } \\
(\mu \mathrm{m})\end{array}$ & $\begin{array}{r}2.467 \\
\pm 0.026\end{array}$ & $\begin{array}{r}0.467 \\
\pm 0.008\end{array}$ & $\begin{array}{r}0.200 \\
+0.008\end{array}$ & $\begin{array}{r}-0.100 \\
\pm 0.023\end{array}$ & $\begin{array}{r}0.100 \\
\pm 0.023\end{array}$ & $\begin{array}{r}0.075 \\
+0.012\end{array}$ & $278 \cdot 674$ \\
\hline $\begin{array}{l}\text { Over-cut } \\
(\mathrm{mm})\end{array}$ & $\begin{array}{c}0.158 \\
\pm 0.00021\end{array}$ & $\begin{array}{c}0.023 \\
\pm 0.00006\end{array}$ & $\begin{aligned} & 0.008 \\
\pm & 0.00006\end{aligned}$ & $\begin{array}{l}0.013 \\
+0.00019\end{array}$ & $\begin{array}{c}0.008 \\
\pm 0.00019\end{array}$ & $\begin{array}{l}-0.010 \\
\pm 0.00009\end{array}$ & $167 \cdot 167$ \\
\hline $\begin{array}{l}\text { Out-of- } \\
\text { roundness } \\
(\mu \mathrm{m})\end{array}$ & $\begin{array}{r}5.111 \\
\pm 1.049\end{array}$ & $\begin{array}{r}1.000 \\
\pm 0.315\end{array}$ & $\begin{array}{r}-0.167 \\
\pm 0.315\end{array}$ & $\begin{array}{r}-0.667 \\
\pm 0.944\end{array}$ & $\begin{array}{r}2.833 \\
\pm 0.944\end{array}$ & $\begin{array}{r}3.000 \\
\pm 0.472\end{array}$ & 54.096 \\
\hline
\end{tabular}

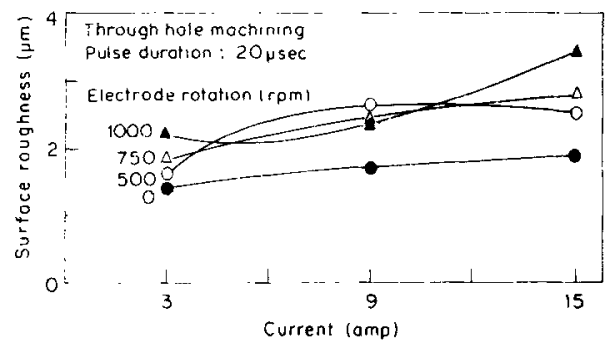

Figure 4. Variation of surface roughness with current and electrode rotation.

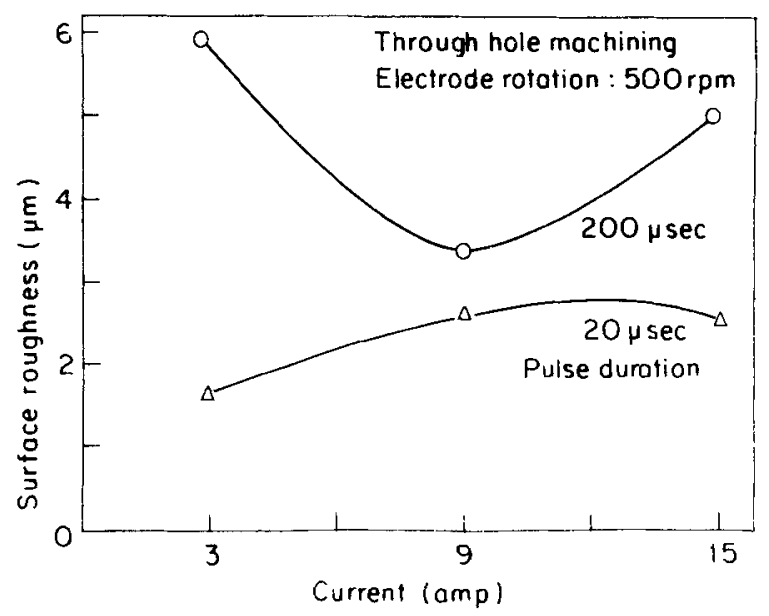

Figure 5. Variation of surface roughness with current and pulse duration.

\section{Results and discussion}

\subsection{Through hole machining}

3.1a Surface roughness variation with electrode rotating speed: The surface roughness $\left(R_{a}\right)$ values obtained in rotary EDM and stationary modes are shown in figures 4 and 5 as a function of electrode rotation, pulse duration and various current 


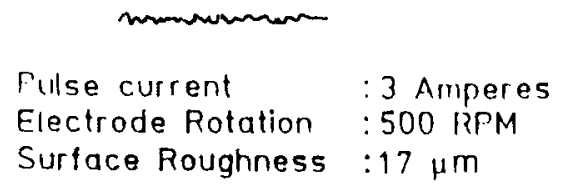

Pulse current : 3 Amperes Electrode Rotation 750 RPM

Surface Roughness : $1.9 \mu \mathrm{m}$

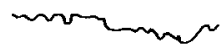

Pulse current : 3 Amperes Electrode Rolation : 1000 RPM Surface Roughness : $2.3 \mu \mathrm{m}$

Pulse current : 3 Amperes

Electrode Rotation :0 RPM Surface Roughness $: 1.4 \mu \mathrm{m}$

monnamennen

Pulse current

Electrode :9 Amperes

:500 RPM

Surface Roughness : $2.7 \mu \mathrm{m}$

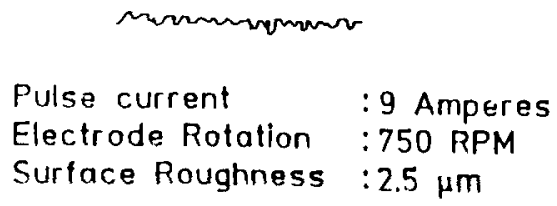

Pulse current :9 Amperes

Electrode Rotation :1000 RPM

Surface Roughness : $2.4 \mu \mathrm{m}$ $\begin{array}{ll}\text { Pulse current } & : 9 \text { Amperes } \\ \text { Electrode Rotation } & : 0 \text { RPM } \\ \text { Surface Roughness } & : 1.7 \mu \mathrm{m}\end{array}$

$\begin{array}{ll}\text { Pulse current } & : 15 \text { Amperes } \\ \text { Electrode Rotation } & : 500 \text { RPM } \\ \text { Surface Roughness } & : 2.5 \mu \mathrm{m}\end{array}$

$\begin{array}{ll}\text { Pulse current } & : 15 \text { Amperes } \\ \text { Electrode Rotation } & : 750 \text { RPM } \\ \text { Surface Roughness } & : 2.8 \mu \mathrm{m}\end{array}$

Pulse current : 15 Amperes

Electrode Rotation : 1000 RPM

Surface Roughness : $3.4 \mu \mathrm{m}$

$\begin{array}{ll}\text { Pulse current } & : 15 \text { Amperes } \\ \text { Electrode Rotation } & : 0 \text { RPM } \\ \text { Surface Roughness } & : 1.9 \mu \mathrm{m}\end{array}$

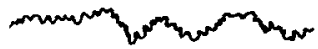

Pulse current :3 Amperes

Electrode Rotation :500 RPM

Pulse Duration $: 200 \mu \mathrm{S}$

Surlace Roughness $: 5.9 \mu \mathrm{m}$

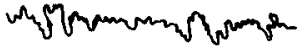

$\begin{array}{ll}\text { Pulse current } & : 15 \text { Amperes } \\ \text { Electrode Rotation } & : 500 \mathrm{RPM} \\ \text { Pulse Duration } & : 200 \mu \mathrm{S} \\ \text { Surface Roughness } & : 4.9 \mu \mathrm{m}\end{array}$

Figure 6. Surface roughness profiles of electro discharge machined surfaces. Pulse duration: $20 \mu \mathrm{sec}$. 
values. Figure 6 shows the surface profiles. Electro-discharge machined surfaces were formed from an integration of microcraters resulting from ejection of molten metal. The size of a crater which depends on the discharge energy, increased with increase of current which mainly contributed to surface roughness. Surface roughness was low at low current and as the current increased, the roughness also increased (figures 4-6) (Soni and Chakraverti 1990a). It was also observed that roughness increased with rotating electrode.

This observation was, however, contradictory to the general observations made by others for other materials. This can be attributed (Sato et al 1986; Kaneko and Tsuchiya 1988; Soni and Chakraverti 1990) to the low thermal and electrical conductivity and high melting temperature of titanium than steel.

It was also observed from figures 5 and 6 that increase in pulse duration resulted in increase in roughness as the discharge took longer duration which created large craters. Short pulse duration allowed close overlapping of craters and hence a good surface finish was obtained. A controlled reduction of the discharge energy to a very small extent was necessary to improve the accuracy and surface finish (Sato et al 1986).

3.1b Dimensional accuracy with rotary EDM: Figures 7-10 show that over-cut also increases with increase in current values and pulse duration. It was also observed that over-cut was higher with rotating electrode. Figures 9 and 10 show the geometry of the holes. There was a natural improvement in the geometry of hole machined with increase of electrode rotation.

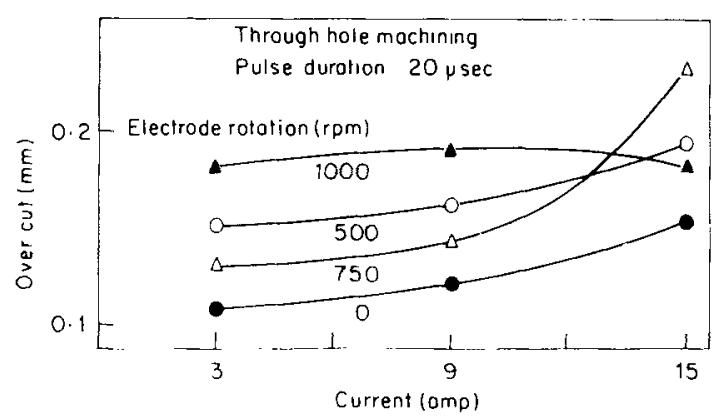

Figure 7. Variation of over-cut with current and electrode rotation.

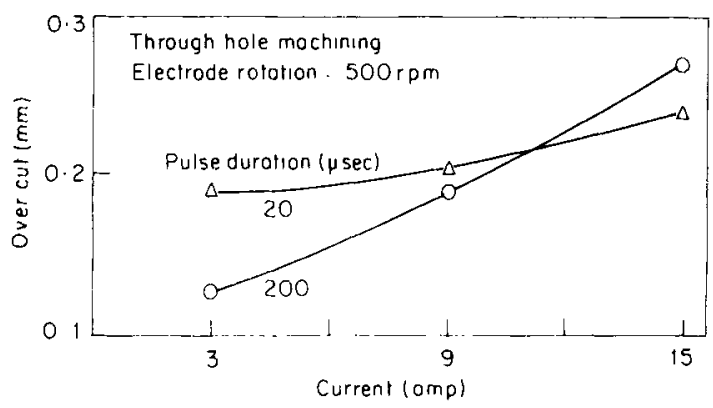

Figure 8. Variation of over-cut with current and pulse duration. 

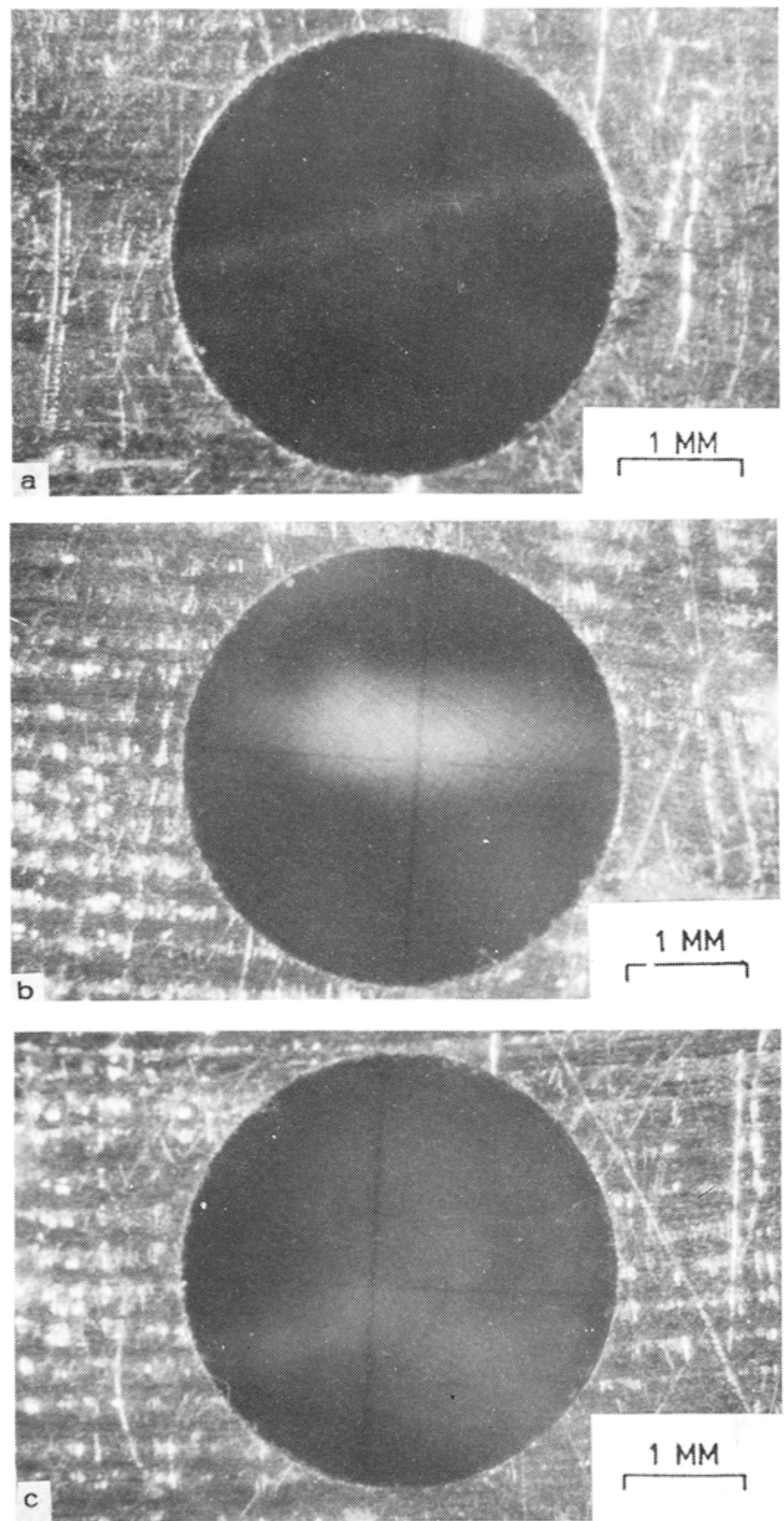

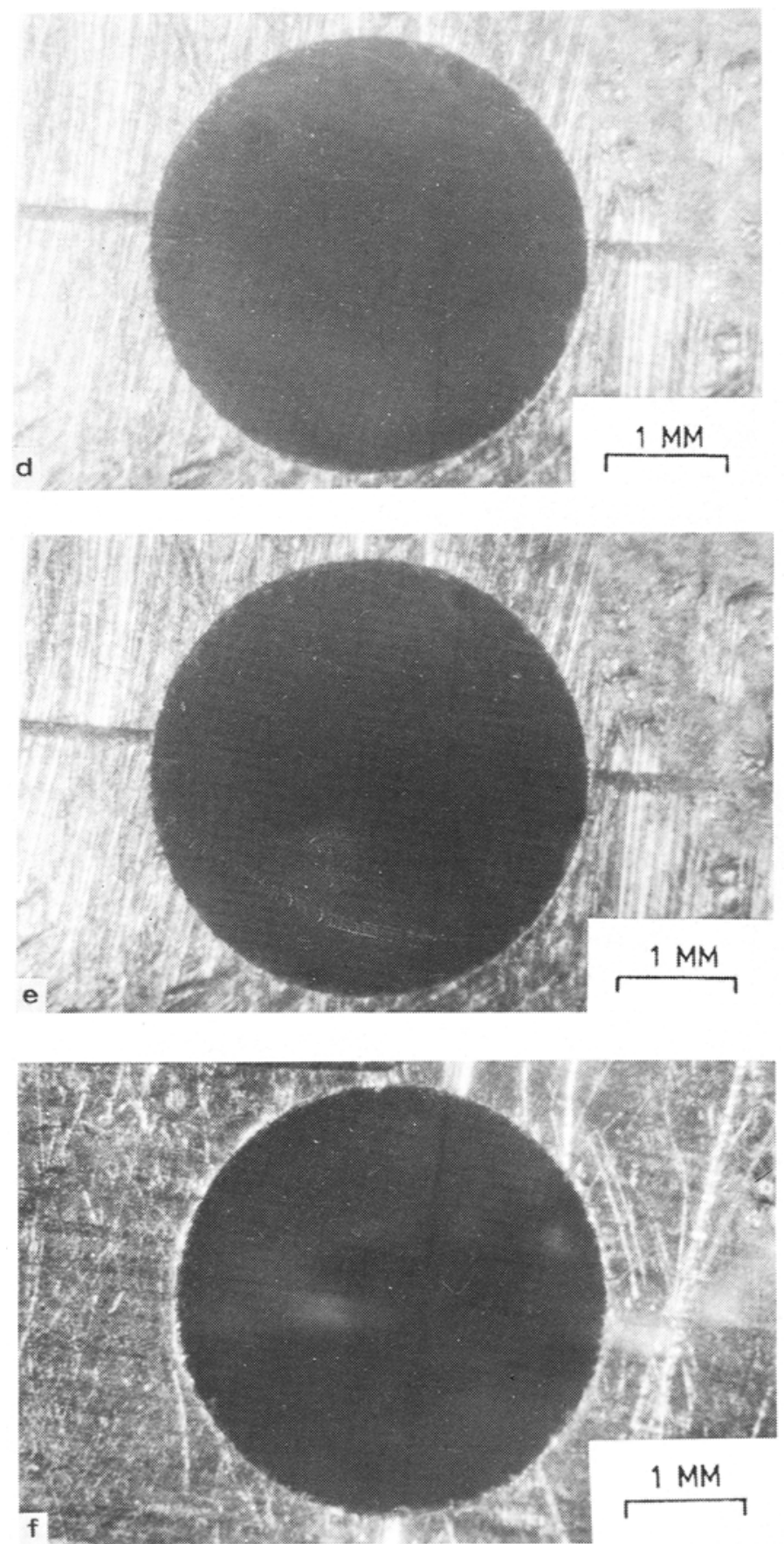

Figure 9. Photomicrographs of electro-discharge machined holes. Hole $\varnothing 3 \mathrm{~mm}$, Pulse duration: $20 \mu \mathrm{sec}$. Through hole machining (a. $3 \mathrm{amp}, 750 \mathrm{rpm}$; b. $9 \mathrm{amp}, 1000 \mathrm{rpm} ; \mathbf{c} .3 \mathrm{amp}$, 1000 rpm; d. 15 amp, 750 rpm; e. 9 amp, 500 rpm; f. 3 amp, 0 rpm). 

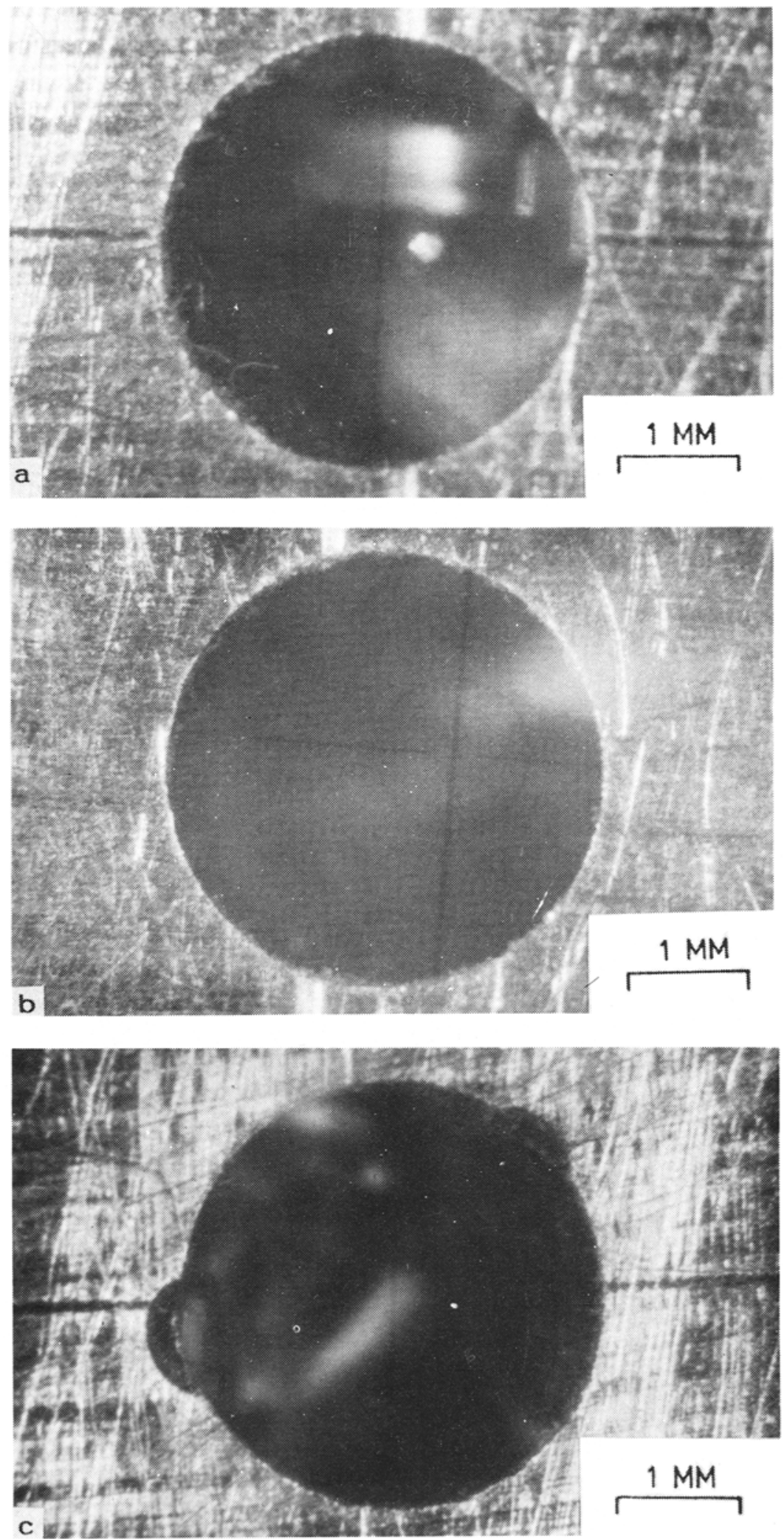


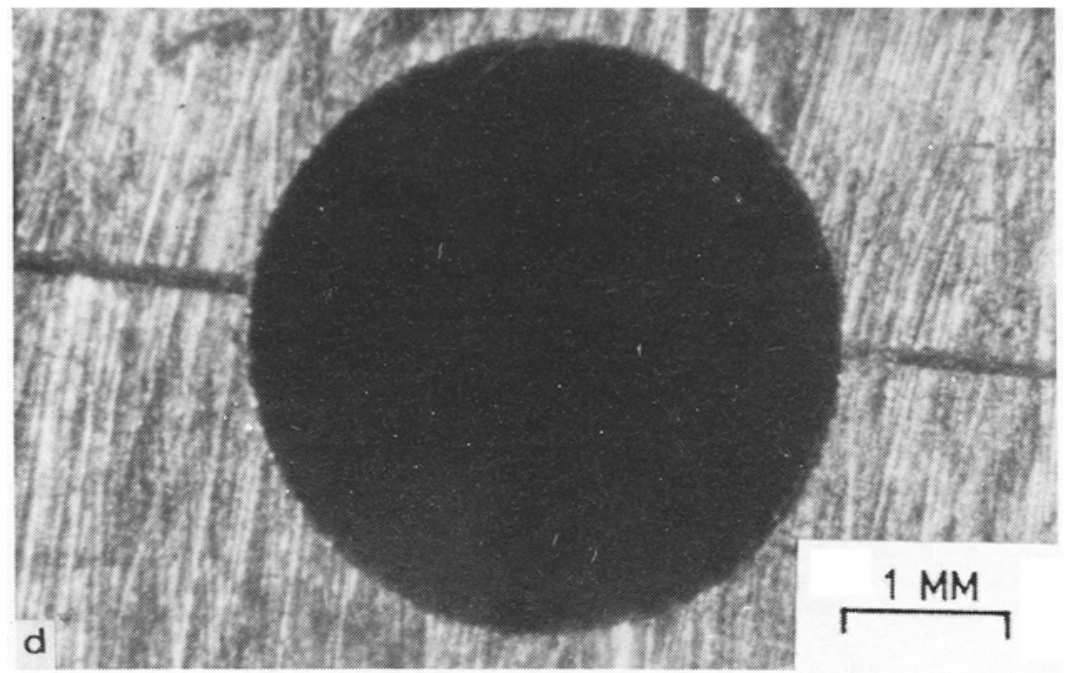

Figure 10. Photomicrographs of electro-discharge machined holes. Hole $\varnothing 3 \mathrm{~mm}$. (a. $3 \mathrm{amp}$, $750 \mathrm{rpm}$; b. $3 \mathrm{amp}, 200 \mu \mathrm{sec}, 500 \mathrm{rpm}$; c. $3 \mathrm{amp}, 0$ rpm; d. 9 amp, $200 \mu \mathrm{sec}, 500 \mathrm{rpm}$ ).

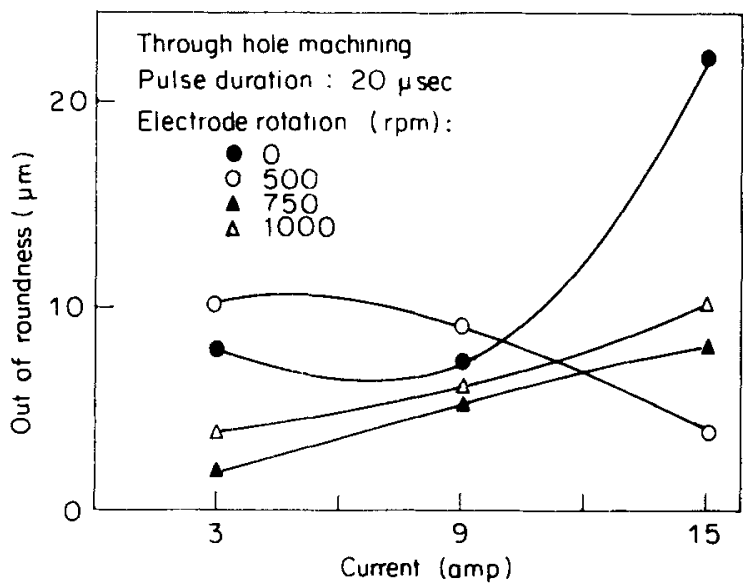

Figure 11. Variation of out-of-roundness with current and electrode rotation.

3.1c Out-of-roundness with rotary EDM: Figures 11 to 16 give the variation of out-of-roundness with current and rotation. Out-of-roundness increased with the current and was negligible. This was because the side of the electrode moved with respect to side wall of the hole (Soni and Chakraverti 1990a). It was observed that out-of-roundness improved with rotating electrode at higher rotations. The effect of ovality in electrode was also reduced due to rotation. Hence, the electrode was rotated in order to machine the holes with minimum out-of-roundness, eliminate welding between the machining electrode and workpiece during short circuit, and to flush the debris out in order to increase machining speed (Kaneko and Tsuchiya 1988).

Figures 13-16 show the super imposition of electrode and hole out-of-roundness 


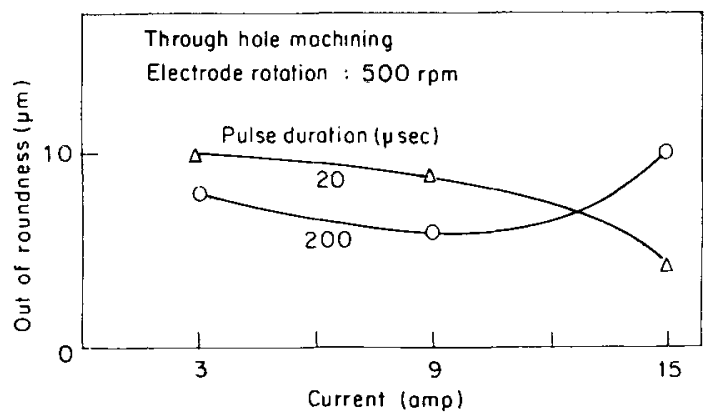

Figure 12. Variation of out-of-roundness with current and pulse duration.
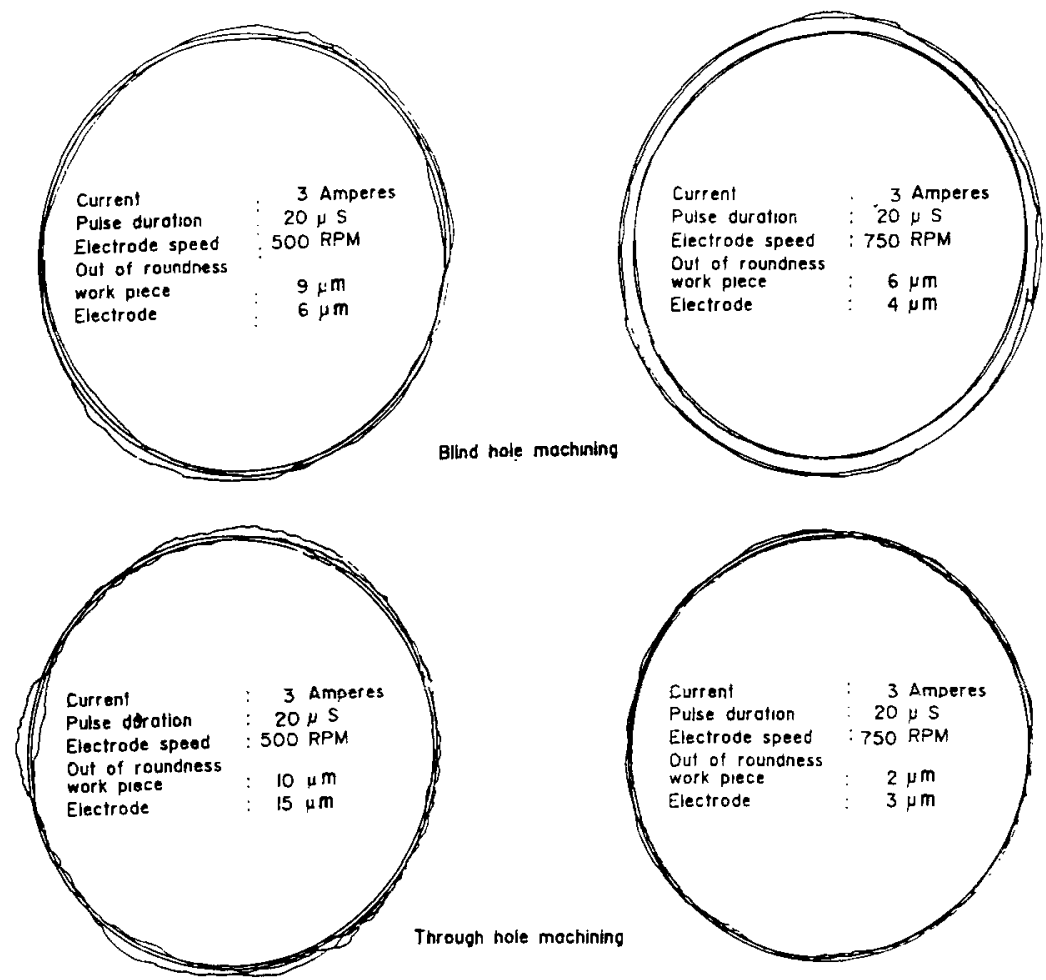

Figure 13. Out-of-roundness and surface profiles of sides of holes. Magnification $(\times 500)$.

and roundness profiles. It was observed that the electrode roundness and surface profiles were better than the holes.

\subsection{Blind hole machining}

3.2a Surface roughness, accuracy and out of roundness: Figures 17 and 18 compare the over-cut and out-of-roundness for blind and through hole machining. It was observed that through hole machining was better than that of blind hole machining, because debris was more efficiently cleared through a predrilled hole in work piece. 

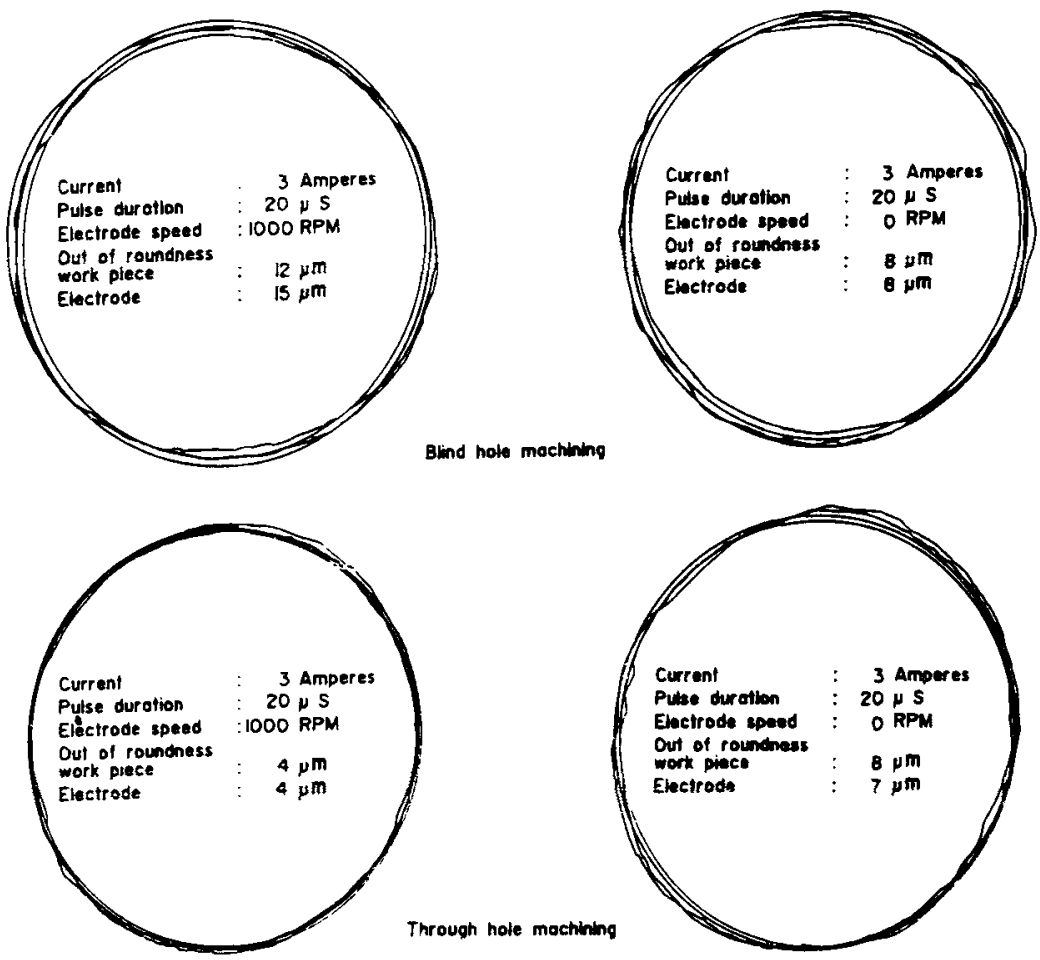

Figure 14. Out-of-roundness and surface profiles of sides of holes. Magnification $(\times 500)$.
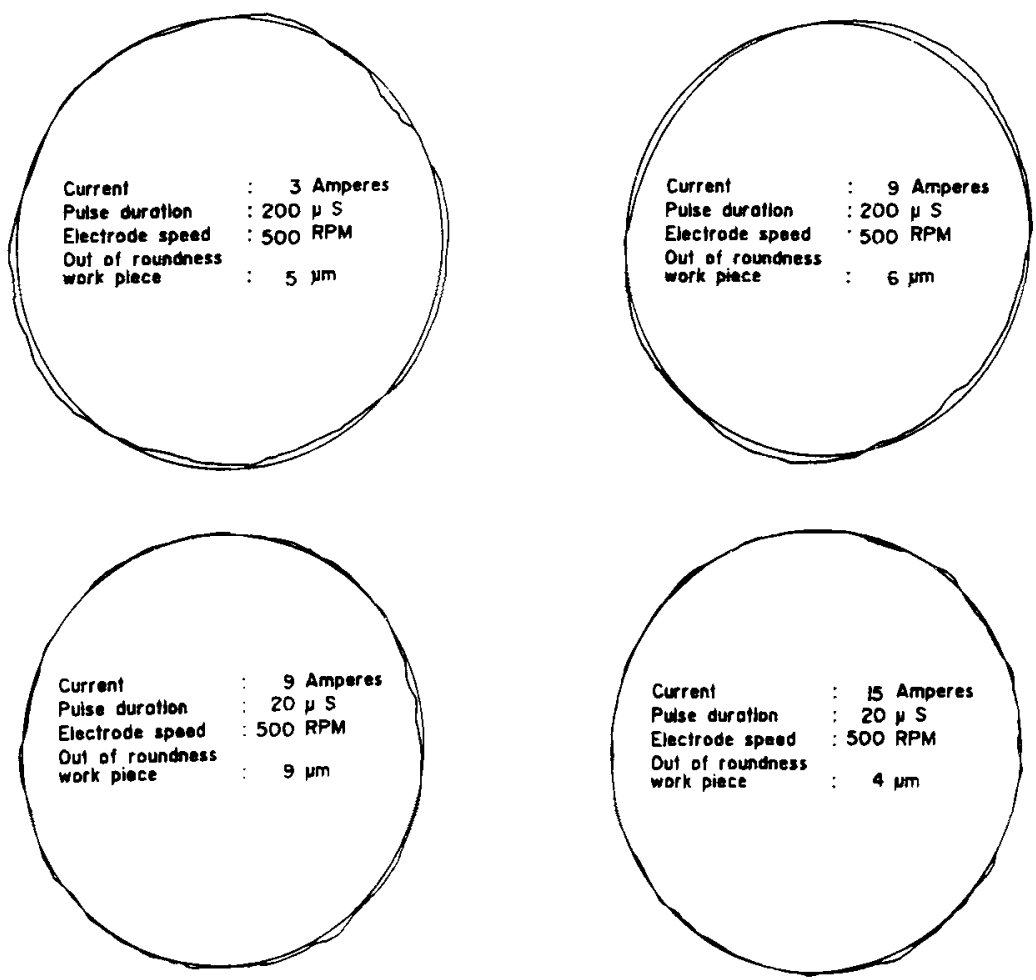

Figure 15. Out-of-roundness and surface profiles of sides of holes. Magnification $(\times 500)$. Through hole machining. 

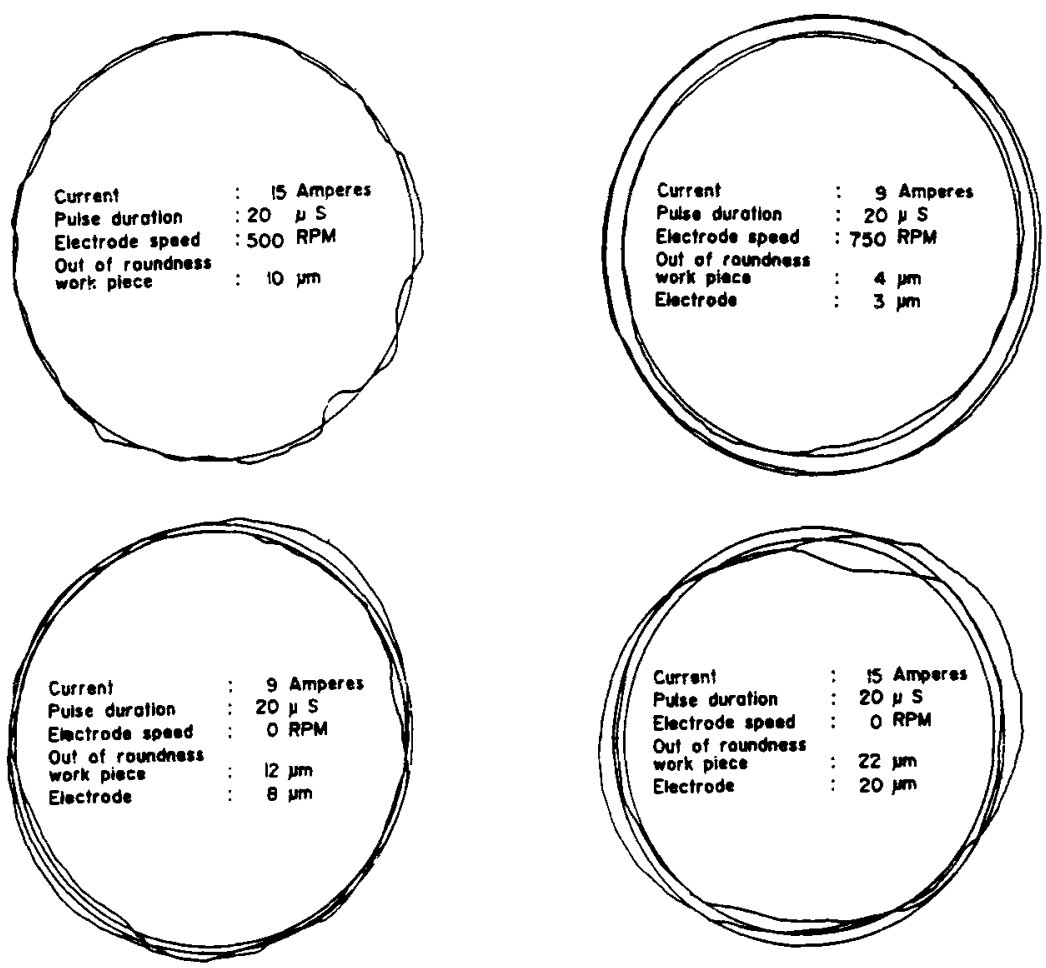

Figure 16. Out-of-roundness and surface profiles of sides of holes. Magnification $(\times 500)$. Through hole machining.

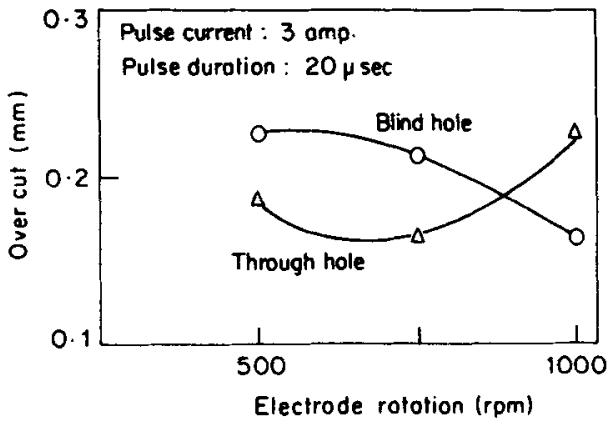

Figure 17. Variation of over-cut with electrode rotation for blind and through hole machining.

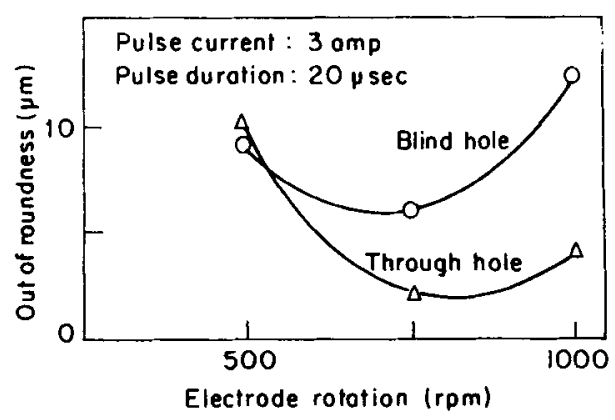

Figure 18. Variation of out-of-roundness with electrode rotation for blind and through hole machining.

In the above investigations it was observed that the overall performance was better using rotating electrode at $750 \mathrm{rpm}$.

\section{Conclusions}

(i) Rotary EDM improves out-of-roundness due to improved flushing.

(ii) Through hole machining is better than blind hole machining with rotating electrode. This is again due to improved flushing. 
Table 4. The estimates of the coefficients and the test of their significance are presented in an ANOVA table. Hypothesis tested are: $\mathrm{H}_{0}: \beta_{i_{j}}=0 . \mathrm{F}_{1 \cdot 111 x=0.051}=4.84$.

\begin{tabular}{lccrrr}
\hline $\begin{array}{l}\text { Coefficient } \\
\text { estimated }\end{array}$ & $\begin{array}{c}\text { Estimate } \\
\left(\beta_{i j}\right)\end{array}$ & d.o.f & \multicolumn{1}{c}{ S.S. } & M.S. & $F_{\text {cal }}$ \\
\hline$\beta_{0}$ & 2.467 & 1 & $54 \cdot 760$ & 54.760 & $1624 \cdot 312^{* *}$ \\
$\beta_{1}$ & 0.467 & 1 & 1.306 & 1.306 & $38 \cdot 759^{* *}$ \\
$\beta_{2}$ & 0.200 & 1 & 0.240 & 0.240 & $7 \cdot 119^{*}$ \\
$\beta_{11}$ & -0.100 & 1 & 0.020 & 0.020 & 0.593 \\
$\beta_{22}$ & 0.100 & 1 & 0.020 & 0.020 & 0.593 \\
$\beta_{12}$ & 0.075 & 1 & 0.022 & 0.022 & 0.667 \\
Due to regression & & 6 & 56.369 & 9.395 & \\
About regression & & 11 & 0.371 & 0.034 & \\
Total & & 17 & 56.74 & 3.337 & \\
\hline
\end{tabular}

$$
\begin{aligned}
& \begin{array}{l}
\text { * Significant }\left(P<5^{\circ}{ }_{0}\right) \quad \text { Coefficient of correlation, } r=1-\frac{\text { SS about regr }}{\text { SS total }} \\
\text { for surface roughness }=1-\frac{0.371}{56.74}=0.9935
\end{array} \\
& \text { ** Highly significant }\left(P<1^{\circ}\right)
\end{aligned}
$$

(iii) The rotary mode of EDM is better than stationary mode. Machining of $3 \mathrm{~mm}$ hole at $750 \mathrm{rpm}$ is recommended.

(iv) Surface roughness, over-cut and out-of-roundness increase with increasing current.

\section{References}

Ayers J D and Moore K 1984 Metall. Trans. A15 1117

Cochran W G, William G and Cox G M 1977 Experimental design, (Bombay: Asia Publishing House)

Das M N and Giri N C 1986 Design and analysis of experiments, (Hyderabad: Wiley Eastern Ltd.)

De Bruyn H E and Delft T H 1978 Ann. CIRP 2393

Erden A 1982 International machine tool design and research conference, Manchester, $23 \mathrm{pp} 283$

Faruqui M A and Mishra P 1978 8th AJMTDR conference. Indian Institute of Technology. Bombay, pp 520-529

Kagaya K, Oishi Y and Yada K 1986 Precision Eng. 8157

Kaneko T and Tsuchiya M 1988 Precision Eng. 10157

Kravets A T 1977 Machines \& Tooling 4816

Masuzawa T and Heuvelman C J 1983 Ann. CIRP 32109

Murthi V S R and Philip P K 1987 Int. J. Prod. Res. 25259

Radhakrishnan V and Achyutha B T 1980 J. Inst. Eng. (India) 60217

Sato T, Mizutani T, Yonemachi K and Kawata K 1986 Precision Eng. 8163

Soni J S and Chakraverti G 1990a J. Inst. Eng. (India) 7119

Soni J S and Chakraverti G 1990b 14th AIM TDR conference, Indian Institute of Technology, Bombay, p. 297 